\title{
Changing patterns of Insulin Resistance in Polycystic Ovary Syndrome
}

\author{
R LAILA ${ }^{1}$, N MAHMUD $^{2}$, M NARGIS $^{3}$, T.A. CHOWDHURY ${ }^{4}$
}

\begin{abstract}
:
Objective (s):Aim of the study was to explore the changing patterns of insulin resistance in PCOS women.

Methods: The study was conducted at CARE, department of Obstetrics and Gynecology and Biomedical Research Group, BIRDEM hospital. A total number of 103 PCOS women of 1536 years were included in the present study. They were grouped into NGT $(n=68), \operatorname{IGT}(n=30)$, type 2 DM (n=5) according to nature of glucose tolerance. Fasting and glucose stimulated insulin was measured.

Results: In IGT group, fasting and glucose-stimulated insulin level were higher when compared with NGT, but no difference between type 2 DM and NGT group was found. Insulin-glucose ratio (after glucose load) was significantly lower in type 2 DM when compared with NGT group $(p=0.049)$, but there was no difference of insulin-glucose ratio (fasting) between type $2 D M$ and NGT group. PCOS with IGT or Type 2 DM women were more insulin resistant than NGT group. ( $p=0.015, p=0.042$ respectively).

Conclusion: Insulin resistance is a major pathophysiologic feature of PCOS with IGT; however â cell secretory defect is associated with type 2 DM in these subjects.
\end{abstract}

Key words: Polycystic Ovary Syndrome, Insulin Resistance.

\section{Introduction:}

Polycystic ovary syndrome (PCOS) is a common endocrine disorder affecting 5-10\% women of reproductive $a \mathrm{e}^{1}$. It is a syndrome characterized by hyperandrogenism, persistent anovulation, oligomenorrhea or amenorrhea, hirsutism, elevated LH and the accumulation of small cysts in the ovaries. The clinical and biochemical features are heterogenous and there has been much debate as to whether it represents single disorder or several. The most widely acceptable diagnostic criteria is given by the National Institutes of Health (NIH) in 1990 are hyperandrogenism and chronic anovulation in cases in which secondary causes (such as adult onset congenital adrenal hyperplasia, hyperprolactinema and androgen secreting neoplasm) have been excluded ${ }^{2}$.

The etiology of the disease is still unknown ${ }^{3}$. Recent evidences suggest that the underlying disorder may be insulin resistance (IR) and hyperinsulinemia causing excess androgen production ${ }^{4}$. Insulin resistance is a common lesion in both obese and non-obese PCOS women, but obesity contributes an additional component to IR in obese $\mathrm{PCOS}^{5}$. Although the reported incidence of insulin resistance varies, it is estimated to be $50 \%$ in $\mathrm{PCOS}^{6}$. There are several mechanisms for the state of insulin resistance: peripheral target tissue resistance, decreased hepatic clearance or increased pancreatic sensitivity ${ }^{7}$. In PCOS, peripheral insulin resistance is due to a defect beyond activation of the receptor kinase ${ }^{8}$. This would suggest no abnormality in the number of receptors or in receptor function; the impaired insulin signal for glucose transport may be due to a post-receptor problem.

There is an impressive correlation between the degree of hyperinsulinemia, and hyperandrogenism ${ }^{9}$. Most of the evidences support hyperinsulinemia as the primary factor, since turning off the ovary with a $\mathrm{GnRH}$

1. RS \& Assistant Professor, Dept. of Gynae \& Obs, BIRDEM General Hospital-2

2. Consultant, CARE, BIRDEM General Hospital-2.

3. Research Officer, BIRDEM.

4. Professor \& Chief Consultant, Dept. of Gynae \& Obs, BIRDEM General Hospital-2. 
agonist does not change the hyperinsulinemia or insulin resistance ${ }^{10}$. Marked hyperinsulinemia synergizes with LH to stimulate ovarian androgen production causing ovarian theca cell hyperplasia, anovulation, menstrual disturbance and hirsutism.

In a state of insulin resistance, the pancreas produces an increase amount of insulin in response to normal metabolic homeostasis. Diabetes develops when this increased production cannot keep up with the metabolic needs and relative insulin deficiency occurs. Increased body size and increased amount of visceral fat are associated with worsening insulin sensitivity ${ }^{11}$. However, insulin resistance is also seen in lean patients with $\mathrm{PCOS}^{6,12}$.

\section{Materials and Methods:}

The study was conducted at CARE, department of Obstetrics and Gynecology and Biomedical Research Group, BIRDEM hospital during the period of January 2006-Decemember 2008.

A total number of 103 PCOS women of reproductive age (15-40 years) were included in the study. An informed consent was obtained from the subjects before the study.

According to Rotterdam criteria 2003, PCOS was diagnosed by oligomenorrhea (menstrual cycle interval $>35$ days but $<6$ months duration) or amenorrhea (if no menstruation for 6 months or more), and one or more of the following criteria such as subfertility, obesity, hirsutism, cystic acne, ultrasound evidence of bilateral enlarged ovaries with multiple (10 or more) small subcortical follicles (2-10 $\mathrm{mm}$ in diameter).

PCOS with known diabetes were excluded from the study. Patients with other endocrine disease (for e.g. hyperadrenalism, hypothyroidism) were excluded from the study.

Oral glucose tolerance test (OGTT) was performed in all subjects following the WHO criteria (1999). Blood samples were taken after overnight (8-12 hrs) fasting condition and then 2 hrs after 75 gram of glucose intake. Glucose and insulin levels were measured from both fasting sample and 2 hrs after glucose load. Patients were grouped in three groups- NGT (nonglucose tolerance), IGT (impaired glucose tolerance) and Type $2 \mathrm{DM}$ according to WHO criteria.

Serum insulin (fasting and $2 \mathrm{hrs}$ after glucose load) was assayed by chemiluminescence-based ELISA technique ${ }^{13}$ using automated analyzer (IMMULITE,
USA) with a commercial kit (Diagnostic Products Corporations, USA) (Appendix II).

\section{Calculation of $\beta$-Cell Function and Insulin Sensitivity}

Insulin secretory capacity (as assessed by insulin secretion HOMA â \%) and insulin resistance (as assessed by insulin sensitivity HOMA S \%) were calculated from fasting blood glucose ( $\mathrm{mmol} / \mathrm{L})$ and fasting plasma insulin (pmol/l) values by homeostasis model assessment (HOMA) using HOMA-CIGMA software ${ }^{14}$.

The data were expressed as the mean \pm SD (standard deviation) median, range, number and \% as appropriate. Students unpaired t test, Mann-Whitney $U$ test and $X^{2}$ was used for data analysis. Pearson correlation was performed to determine the association between different variables of interest. $p$-value of $<0.05$ was considered statistically significant. All statistical analyses were performed with the SPSS (Statistical Package for Social Science) software for Windows version 11.5 (SPSS, Inc. Chicago, IL, USA).

\section{Results:}

Clinical Characteristics of the study subjects

PCOS were in reproductive age (15-36 years), mean age $24.4 \pm 5.18$ years. Mean height of the subjects were $1.57 \pm 0.087$ meter, weight was $62.08 \pm 20.15 \mathrm{~kg}$, and BMI was $25.84 \pm 5.54 \mathrm{~kg} / \mathrm{m}^{2}$. The detailed anthropometry was shown in Table 1. Of these 103 PCOS women, typical physical characteristics, such as acne, hirsutism was present in $91.3 \%$ cases and $48.5 \%$ PCOS had family history of diabetes.

Table-I

Clinical Characteristics of the study subjects

\begin{tabular}{lcc}
\hline Parameter & \multicolumn{2}{c}{ PCOS $(\mathrm{n}=103)$} \\
\cline { 2 - 3 } & Mean & $\pm \mathrm{SD}$ \\
\hline Age $(\mathrm{yr})$ & 24.4 & \pm 5.18 \\
Height $(\mathrm{m})$ & 1.57 & \pm 0.087 \\
Weight $(\mathrm{kg})$ & 62.08 & \pm 20.15 \\
BMI $\left(\mathrm{kg} / \mathrm{m}^{2}\right)$ & 25.84 & \pm 5.54 \\
Waist $(\mathrm{cm})$ & 90.05 & \pm 13.94 \\
Hip $(\mathrm{cm})$ & 97.09 & \pm 11.79 \\
Waist $/$ hip ratio & 0.93 & \pm 0.13 \\
& $\mathrm{~N}$ & $\%$ \\
Typical Physical & & \\
Characteristics & 94 & $91.33 \%$ \\
Positive family history of & 50 & $48.05 \%$ \\
diabetes & & \\
\hline
\end{tabular}

Results are expressed as Mean $\pm \mathrm{SD}$, or No and \% as appropriate 
Frequency distribution of PCOS subjects according to glucose tolerance

Among 103 PCOS women, 30 (29.1\%) showed impaired glucose tolerance; (IGT: 7.8-11.0) and 5 (4.9\%) showed type 2 diabetes; T2 DM (fasting >7.0, $2 \mathrm{hr}$ after glucose $>11.1$ ) and $68(66 \%)$ showed normal glucose tolerance; NGT.

\section{Table-II}

Frequency distribution of PCOS subjects according to glucose tolerance

\begin{tabular}{lcc}
\hline Groups & No. & $\%$ \\
\hline NGT $(<7.8)$ & 68 & $66 \%$ \\
IGT $(7.8-11.0)$ & 30 & $29.1 \%$ \\
T2 DM $(>11.1)$ & 5 & $4.9 \%$ \\
\hline
\end{tabular}

NGT, Normal glucose tolerance; IGT, Impaired glucose tolerance; T2 DM, Type 2 diabetes mellitus;
Insulinemic and glycemic status of different groups of PCOS

Fasting insulin $(\mu \mathrm{IU} / \mathrm{ml})$, insulin AG of IGT were significantly higher compared with NGT $(p=0.02$ and 0.049 respectively). But these parameters were not significantly different in T2 DM ( $p=0.067,0.0149$ respectively). There was no significant difference in fasting insulin glucose ratio among the groups but insulin glucose ratio after 2 hr glucose load of T2 DM was decreased significantly when compared with NGT [Median (Range); 6.46 (4.9516.12) vs. 12.58 (1.93-56.23); $p=0.049]$

\section{Insulin sensitivity and â cell function of different groups of PCOS}

Insulin sensitivity (Homa \%S) was significantly decreased in IGT and T2 DM when compared with NGT ( $p=0.015,0.042$ respectively) but there was no significant difference in â cell function (Homa \%B) in the three groups of PCOS (Table 5).

Table-III

Insulinemic and glycemic status of different groups of PCOS

\begin{tabular}{|c|c|c|c|c|c|c|}
\hline \multirow[t]{2}{*}{ Parameter } & \multicolumn{2}{|c|}{ NGT $(n=68)$} & \multicolumn{2}{|c|}{ IGT $(n=30)$} & \multicolumn{2}{|c|}{ T2 DM $(n=5)$} \\
\hline & Median & Range & Median & Range & Median & Range \\
\hline Fasting insulin $(\mu \mathrm{lU} / \mathrm{ml})$ & 10 & $2.80-66.30$ & 12.95 & $6.30-28.0$ & 16.1 & $11.4-30.3$ \\
\hline Insulin AG ( $\mu \mathrm{IU} / \mathrm{ml})$ & 79 & 13.3-388 & 105 & $11.7-400$ & 106 & 69.8-187 \\
\hline Insulin/Glucose (Fasting) & 2.41 & $0.64-15.94$ & 3.03 & $1.15-7.03$ & 2.93 & $1.48-4.09$ \\
\hline Insulin/Glucose (2 hr AG) & 12.58 & $1.93-6.23$ & 11.66 & $1.34-43.96$ & 6.46 & 4.95- 16.12 \\
\hline
\end{tabular}

p value

\begin{tabular}{lccc}
\hline & NGT vs. IGT & NGT vs. T2 DM & IGT vs. T2 DM \\
\hline Fasting insulin $(\mu \mathrm{IU} / \mathrm{ml})$ & $0.02^{*}$ & 0.067 & 0.524 \\
Insulin AG $(\mu \mathrm{IU} / \mathrm{ml})$ & $0.049^{\star}$ & 0.149 & 0.777 \\
Insulin/Glucose (Fasting) & 0.091 & 0.382 & 0.850 \\
Insulin/Glucose (2 hr AG) & 0.584 & $0.049^{\star}$ & 0.073 \\
\hline
\end{tabular}

Results are expressed as Mean $\pm \mathrm{SD}$, Median (Range); or No (\%) as appropriate; Difference between groups was calculated using unpaired students t test and Mann-Whitney $U$ test where appropriate. ${ }^{*} p$ value $<0.05$ is considered statistically significant

Table-IV

Insulin sensitivity and $\beta$ cell function of different groups of PCOS

\begin{tabular}{|c|c|c|c|c|c|c|}
\hline \multirow[t]{2}{*}{ Parameter } & \multicolumn{2}{|c|}{ NGT $(n=68)$} & \multicolumn{2}{|c|}{ IGT $(n=30)$} & \multicolumn{2}{|c|}{ T2 DM $(n=5)$} \\
\hline & Median & Range & Median & Range & Median & Range \\
\hline (Homa \%S) & 64.05 & $11.6-240.2$ & 52.65 & $24.2-101.3$ & 40.4 & $20.6-61.8$ \\
\hline (Homa \%B) & 162.2 & 68.4-790.4 & 185.75 & $76.4-437.5$ & 144.3 & $61.1-210.2$ \\
\hline
\end{tabular}

p value

\begin{tabular}{lccc}
\hline & NGT vs. IGT & NGT vs.T2 DM & IGT vs.T2 DM \\
\hline (Homa \%S) & $0.015^{\star}$ & $0.042^{\star}$ & 0.322 \\
$($ Homa \%B) & 0.502 & 0.295 & 0.203 \\
\hline
\end{tabular}

Results are expressed Median and Range; Difference between groups was calculated Mann-Whitney $U$ test; ${ }^{*} p$ value $<0.05$ is considered statistically significant 


\section{Discussion:}

In the present study we observed that both fasting and glucose-stimulated insulin were significantly higher in IGT with PCOS than NGT with PCOS. But no difference of fasting and glucose-stimulated insulin was observed between type 2 DM and NGT PCOS. Ehrmann et a $1{ }^{15}$ also found glucose stimulated insulin level of type 2 DM PCOS was lower than normal PCOS. Insulin-glucose ratio (after glucose load) was significantly lower in type 2 DM with PCOS when compared with NGT with PCOS. These results indicate that there may be an inappropriately low insulin response to glucose in Type $2 \mathrm{DM}$ as there could be some â cell secretory defects.

We found that both IGT and type 2 DM were more insulin resistant than NGT with PCOS, but no difference was found between IGT vs. type 2 DM. So insulin resistance was a prime factor for developing IGT in PCOS and â cell secretory dysfunction was also an important risk factor for the developing type 2 DM. Lillioja et $\mathrm{a}^{16}$ has found consistently a significant decrease in insulin meditated glucose disposal in both lean and PCOS women.

It is now clear that PCOS is often associated with profound insulin resistance as well as with defects in insulin secretion. These abnormalities, together with obesity, explain the substantially increased prevalence of glucose intolerance in PCOS. Moreover, since PCOS is an extremely common disorder, PCOSrelated insulin resistance is an important cause of NIDDM in women.

PCOS women also have impaired fibrinolytic activity with increased circulating levels of plasminogen activator inhibitor, PAI-1. Elevated PAI-1 levels are associated with insulin resistance and are considered an independent cardiovascular risk factor by increasing the risk of intravascular thrombosis. Several cross-sectional studies suggest that PCOS women may indeed be at increased risk for cardiovascular disease.

\section{Conclusion:}

Insulin resistance is a major pathophysiologic feature of IGT in PCOS; however, $\beta$ cell secretory defect is associated with type $2 \mathrm{DM}$ in these subjects.

Women with PCOS are at high risk for gestational diabetes and in long term development of type $2 \mathrm{DM}$.
Therefore, an early diagnosis of insulin resistance is crucial to reduce the incidence and severity of these potent risks.

\section{References:}

1. Knochenhauer ES, Key TJ, Kahsar-Miller M, Waggoner W, Boots LR, Azziz R. Prevalence of the polycystic ovary syndrome in unselected black and white women of the southeastern United State: a perspective study. J Clin Endocr Metab 1999; 83: 3078-3082.

2. Zawadzki J, Dunaif A. Diagnostic criteria for polycystic ovary syndrome: towards a rational approach. In: Dunaif A, Givens JR. Haseltimer FP. Merriam GR. Editors. Polycystic ovary syndrome. Current issues in endocrinology and metabolism. $1^{\text {st }}$ ed. Boston (MA): Blackwell Scientific Publications. 1992; 377-384.

3. Dewharts. Textbook of obstetrics and gynecology for postgraduates . $6^{\text {th }}$ edn. pp 46-48.

4. Satter N, Fleming R, Greer AL. Clinical review. Br Med J 1998; 317: 329-332.

5. Morales AJ, Laughlin GA, Buztow T. Insulin, somatotrpic and LH axis in lean and obese women with PCOS, common and distinct feture. J Clin Endocrinol \& Metab 1996; 81: 2854-64.

6. Dunaif A, Finegood DT. B-cell dysfunction independent of obesity and glucose intolerance in the polycystic ovary syndrome. J Clin Endocrinol Metab 1996; 81: 942-947.

7. Ciaraldi TP, Eiroeiy A, Madar Z, Reichart D, Olefsky JM, Yen SC. Cellular mechanism of insulin resistance in PCOS. J Clin Endocrinol Metab. 1992; 75: 557.

8. Reavens GM. Role of insulin resistance in human disease. Diabetes 1998; 37: 1595-1598.

9. Nestler J, Powers L, Matt D, Sterigold K, Plymate $S$, Rittmaster RS, et al. A direct effect of hyperinsulinemia on sex hormone binding globulin levelsmin obese women with PCOS. J Clin Endocrinol Metab 1991; 72: 83-89.

10. Dunaif A, Green G, Weit WF, Dobrjansky A. Suppression of hyperandrogenism does not improve peripheral or hepatic insulin resistance in the PCOS. J Clin Endocrinal Metab 1990; 70: 699. 
11. Dunaif A, Graf M, Mandeli J, Laumas V, Dobrjansky A. Characterization of groups of hyperandrogenic women with acanthosis nigricans, impaired glucose tolerance, and/or hyperinsulinemia. J Clin Endocrinol Metab 1987; 65: 499- 507.

12. Eharmann DA, Sturis J, Byrne MM, Karrison T, Rosenfield R, Polorsky K. Insulin secretory defect in PCOS, relationship to insulin sensitivity and family history of NIDDM. J Clin Invest 1995; 96: 520-522.

13. Bates HM, Insulinoma and pheochromocytoma, Lab Management, 1983;21: 11-12.
14. Levy JC, Matthews DR \& Hermans MP, Correct Homeotasis Model Assessment (HOMA) Evaluation Uses the computer program, Diabetes Care, 1998, 21: 2191-2192.

15. Ehrmann DA, Barnes RB, Rosenefield RL, Cavaghan MK, Imperial J. Prevalence of IGT and diabetes in women with PCOS. Diabetes Care 1999; 22: 141-146.

16. Lillioja S, Mott D, Sparul M, et al. Insulin resistance and insulin secretory dysfunction as precursor of NIDDM. N Engl J Med 1993;329(27): 1988-1992. 